\title{
Over 30 million psychedelic users in the United States [version
}

\section{1; peer review: 2 approved]}

\section{Teri S Krebs, Pål-Ørjan Johansen}

Department of Neuroscience, Faculty of Medicine, Norwegian University of Science and Technology, Trondheim, Norway

\author{
V1 First published: 28 Mar 2013, 2:98 \\ https://doi.org/10.12688/f1000research.2-98.v1 \\ Latest published: 28 Mar 2013, 2:98 \\ https://doi.org/10.12688/f1000research.2-98.v1
}

\section{Abstract}

We estimated lifetime prevalence of psychedelic use (lysergic acid diethylamide (LSD), psilocybin (magic mushrooms), mescaline, and peyote) by age category using data from a 2010 US population survey of 57,873 individuals aged 12 years and older. There were approximately 32 million lifetime psychedelic users in the US in 2010; including $17 \%$ of people aged 21 to 64 years ( $22 \%$ of males and $12 \%$ of females). Rate of lifetime psychedelic use was greatest among people aged 30 to 34 (total $20 \%$, including $26 \%$ of males and $15 \%$ of females).

\section{Keywords}

Psychedelic, United States, magic mushrooms, psilocybin, mescaline, peyote, LSD, lifetime prevalence

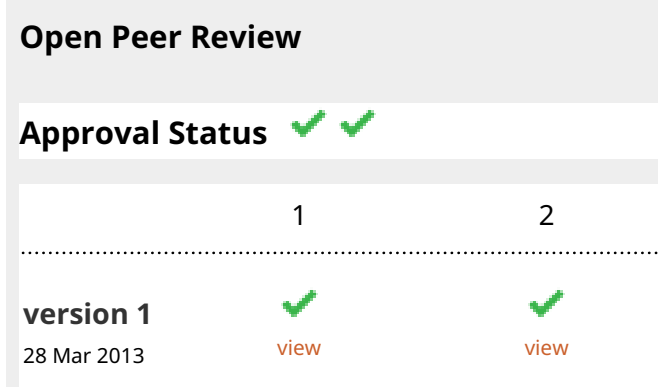

1. Wayne D. Hall, University of Queensland, St Lucia, Australia

2. Dave Nichols, Purdue University, West Lafayette, IN, USA

Any reports and responses or comments on the article can be found at the end of the article.

\section{Corresponding author: Teri S Krebs (krebs@ntnu.no)}

Competing interests: No competing interests were disclosed.

Grant information: Both authors were supported by the Research Council of Norway, grant number 185924.

The funders had no role in study design, data collection and analysis, decision to publish, or preparation of the manuscript.

Copyright: $\odot 2013$ Krebs TS and Johansen PØ. This is an open access article distributed under the terms of the Creative Commons Attribution License, which permits unrestricted use, distribution, and reproduction in any medium, provided the original work is properly cited.

How to cite this article: Krebs TS and Johansen Pø. Over 30 million psychedelic users in the United States [version 1; peer review: 2 approved] F1000Research 2013, 2:98 https://doi.org/10.12688/f1000research.2-98.v1

First published: 28 Mar 2013, 2:98 https://doi.org/10.12688/f1000research.2-98.v1 


\section{Introduction}

The classical serotonergic psychedelics, LSD (lysergic acid diethylamide), psilocybin ("magic mushrooms"), and mescaline (peyote and other cacti), have their main mechanism of action at the serotonin $2 \mathrm{~A}$ receptor $\left(5-\mathrm{HT}_{2 \mathrm{~A}}\right)$, produce similar, often indistinguishable subjective effects, and elicit cross-tolerance ${ }^{1,2}$. The mechanisms of action, subjective effects, and risk profile of the classical serotonergic psychedelics distinguishes them from other drugs sometimes also labeled "hallucinogens", such as entactogens, like methylenedioxymethamphetamine (MDMA; ecstasy) that act primarily at serotonin transporters, or dissociative anesthetics, like phencyclidine $(\mathrm{PCP})$ or ketamine that act primarily at NMDA glutamate receptors ${ }^{1}$.

Prevalence data on psychedelic use in the US is often reported for LSD alone (ignoring psilocybin and mescaline), or for psychedelics grouped together with PCP (popular in the 1970s), MDMA (popular since the 1990s), and/or other "hallucinogens" (some older estimates of hallucinogen use even included cannabis, amphetamine, and cocaine as hallucinogenic drugs), or for use among teenagers but not adults. Here, we present estimated lifetime prevalence of psychedelic use by age category using data from a large US population survey.

\section{Methods}

We examined the estimated lifetime use of psychedelics by age based on 2010 data of the National Survey on Drug Use and Health (NSDUH). Results are presented for males and females separately. We counted participants as having any lifetime psychedelic use if they reported ever using LSD, psilocybin, mescaline, or peyote. The use of mescaline and peyote were combined into one category because mescaline is the active substance of the peyote cactus, but peyote use was also examined separately. Current age was only available as a categorical variable. This study was exempt from review by our Regional Committee for Medical Research Ethics because all data are available in the public domain without any identification of personal information.

\section{Data source}

The annual NSDUH survey provides estimates of substance use and mental health indicators from a randomly-selected sample representative of the US civilian non-institutionalized population aged 12 and older. The Substance Abuse and Mental Health Services Administration (SAMHSA) of the US Department of Health and Human Services is responsible for the NSDUH study design and methods of assessment. Trained interviewers met the randomlyselected participants in their homes, and participants listened to recorded questions via headphones and then entered their answers directly into a computer, providing a highly confidential and standardized setting. The response rate was approximately $78 \%$. In addition, approximately $10 \%$ of participants were excluded from the public use data file, either because of excessive missing data on drug use or because they were excluded at random in order to increase anonymity. The total number of respondents in the public use file was 57,873 . Detailed information on the sampling and data collection methods, including interview instructions and questionnaires, confidentiality and informed consent are available on the SAMHSA website (http://oas.samhsa.gov/nsduh.htm).

\section{Data analysis}

Estimates were calculated using the online Survey Documentation Analysis from the Inter-university Consortium for Political and Social Research (http://dx.doi.org/10.3886/ICPSR32722.v3). Calculations of estimated population percentages and extrapolated total numbers of psychedelic users in the US took into account the weights provided with the NSDUH public use data file. Variance estimates took into account the complex sample design of the NSDUH survey using Taylor series linearization. Respondents with missing data on psychedelic use (less than $1 \%$ of the respondents) were assumed to have no use.

\section{Results}

An estimated 32 million (95\% confidence interval (CI): 30 to 33 million) US residents in 2010 reported lifetime use of LSD ( 23 million, 95\% CI: 22 to 25 million), psilocybin ( 21 million, 95\% CI: 20 to 22 million), mescaline (11 million, 95\% CI: 10 to 12 million), or peyote (6 million, $95 \%$ CI: 5 to 7 million).

Figure 1 shows the rate of lifetime psychedelic use in the US in 2010 by age category and gender. Lifetime rate of psychedelic use among people aged 50 to 64 years (the "baby boomer" generation) was similar to the rate among people aged 21 to 49 years. Among people aged 21 to 64 years, $17 \%$, (95\% CI: $15 \%$ to $18 \%)$ reported ever using LSD, psilocybin, or mescaline, including 22\% (95\% CI: $21 \%$ to $23 \%$ ) of males and $12 \%(11 \%$ to $13 \%)$ of females. Prevalence of psychedelic use was low among people aged 65 and older (total $1.3 \%, 95 \%$ CI: $0.8 \%$ to $2.1 \%$ ). Rate of lifetime psychedelic use was greatest among people aged 30 to 34 years (total 20\%, 95\% CI: $18 \%$ to $22 \%$ ), with $26 \%$ (95\% CI: $23 \%$ to $29 \%$ ) of males and $15 \%$ (95\% CI: $13 \%$ to $17 \%$ ) of females.

\section{Discussion}

Psychedelics continue to be widely used in the US. Common reasons given for using psychedelics include curiosity, mystical experiences, and introspection ${ }^{3}$. Rates of lifetime psychedelic use are greater in males than in females. Overall rates of lifetime psychedelic use are roughly the same among the "baby boomers" and younger adults. However, psilocybin was more common among younger adults, while LSD and mescaline or peyote were more common among older adults. Use of psilocybin mushrooms has increased since the 1970s in the US and worldwide, likely due to dissemination of simple home cultivation techniques, instructions on finding wild mushrooms, and information about effects and methods of psilocybin mushroom use $\mathrm{e}^{4}$. This was a retrospective cross-sectional study. Self-reports of drug use behaviors could be influenced by memory errors and under-reporting; however, a 

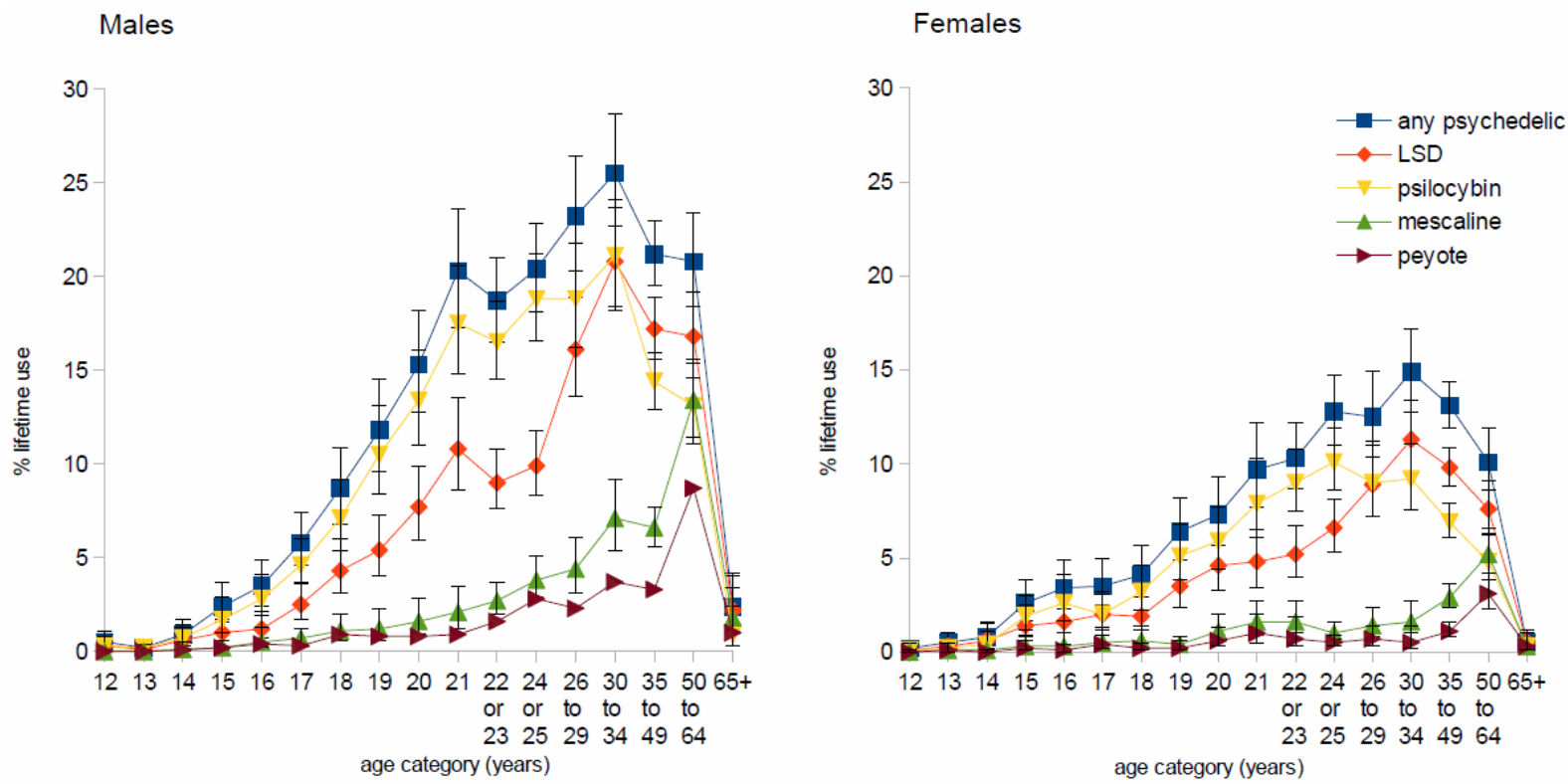

Figure 1. Lifetime psychedelic use by age and gender in the US in $\mathbf{2 0 1 0}$. Error bars show 95\% confidence intervals. Any psychedelic includes LSD, psilocybin, mescaline, and/or peyote. Mescaline includes both mescaline and peyote.

14-year longitudinal study reported good consistency over time in the reporting of lifetime LSD use ${ }^{5}$.

\section{Author contributions}

TK conducted the data analysis. Both authors prepared and approved the manuscript for publication.

\section{Competing interests}

No competing interests were disclosed.
Grant information

Both authors were supported by the Research Council of Norway, grant number 185924.

The funders had no role in study design, data collection and analysis, decision to publish, or preparation of the manuscript.

\section{Acknowledgments}

The Substance Abuse and Mental Health Data Archive provided the data files from the National Survey on Drug Use and Health, which was sponsored by the Office of Applied Studies of the Substance Abuse and Mental Health Services Administration.

1. Nichols DE: Hallucinogens. Pharmacol Ther. 2004; 101(2): 131-181. PubMed Abstract | Publisher Full Text

2. González-Maeso J, Weisstaub NV, Zhou M, et al:: Hallucinogens recruit specific cortical $5-\mathrm{HT}(2 \mathrm{~A})$ receptor-mediated signaling pathways to affect behavior. Neuron. 2007; 53(3): 439-52. PubMed Abstract | Publisher Full Text

3. Hallock RM, Dean A, Knecht ZA, et al:: A survey of hallucinogenic mushroom use, factors related to usage, and perceptions of use among college students.

Drug Alcohol Depend. 2012; 130(1-3): 245-8. PubMed Abstract | Publisher Full Text

4. Andersson C, Kristinsson J, Gry J: Occurrence and use of hallucinogenic mushrooms containing psilocybin alkaloids. Nordic Council of Ministers. 2009. Reference Source

5. Johnston LD, O'Malley PM: The recanting of earlier reported drug use by young adults. NIDA Res Monogr. 1997; 167: 59-80. PubMed Abstract 


\section{Open Peer Review}

\section{Current Peer Review Status:}

\section{Version 1}

Reviewer Report 17 April 2013

https://doi.org/10.5256/f1000research.1160.r896

(C) 2013 Nichols D. This is an open access peer review report distributed under the terms of the Creative Commons Attribution License, which permits unrestricted use, distribution, and reproduction in any medium, provided the original work is properly cited.

\section{Dave Nichols}

Department of Physical chemistry and Molecular Pharmacology, Purdue University, West Lafayette, IN, USA

This report is short and well written. It reports on lifetime incidence of use of various psychedelics. Without knowing the frequency of use, however, these data do not indicate whether the use of psychedelics is increasing.

Competing Interests: No competing interests were disclosed.

I confirm that I have read this submission and believe that I have an appropriate level of expertise to confirm that it is of an acceptable scientific standard.

Reviewer Report 03 April 2013

\section{https://doi.org/10.5256/f1000research.1160.r874}

(c) 2013 Hall W. This is an open access peer review report distributed under the terms of the Creative Commons Attribution License, which permits unrestricted use, distribution, and reproduction in any medium, provided the original work is properly cited.

\section{Wayne D. Hall}

University of Queensland, St Lucia, Australia

The paper is concise and well written and I have no major criticisms of the content of the article. The authors have appropriately analysed the best available data on the question that they address namely, what is the estimated life time use of various psychedelic drugs among US adults. They report analyses of a large representative US household survey data on lifetime experience with various psychedelic drugs. My issue is more with what the paper does not say. 
What's missing from the paper is any indication of why the authors' question is worth posing:

1. Why do lifetime rates of psychedelic drug use among US adults matter?

2. Why did they only report lifetime use? Lifetime or ever use can overstate rates of use in the population. I would bet that most psychedelic use is very limited e.g. once or twice during late adolescence and early adulthood. This isn't clear from the lifetime data presented. Some data on frequency of use would make it clearer if most psychedelic use is in fact limited and experimental rather than more persistent as occurs with cannabis and MDMA.

3. Were any data collected on adverse events or experiences? If so, this could be briefly reported.

4. It would be useful to provide a bit more data on the characteristic of psychedelic drug users other than their age and sex. How are they characterised by SES, education, geographic areas of residence and experience with other illicit drugs e.g. cannabis, MDMA and stimulants?

5. What if anything follows from the findings? Should we be concerned about this use or should we regard psychedelic drug use as being of much lower public health concern than the use of other illicit drugs such as cannabis, amphetamine type stimulants, cocaine and opioids?

Competing Interests: No competing interests were disclosed.

I confirm that I have read this submission and believe that I have an appropriate level of expertise to confirm that it is of an acceptable scientific standard.

The benefits of publishing with F1000Research:

- Your article is published within days, with no editorial bias

- You can publish traditional articles, null/negative results, case reports, data notes and more

- The peer review process is transparent and collaborative

- Your article is indexed in PubMed after passing peer review

- Dedicated customer support at every stage

For pre-submission enquiries, contact research@f1000.com

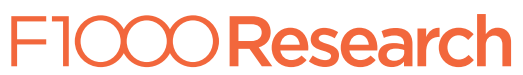

